Journal of Current and Advance Medical Research

July 2018, Vol. 5, No. 2, pp. 68-72

http://www.banglajol.info/index.php/JCAMR

ISSN (Print) 2313-447X

ISSN (Online) 2413-323X

DOI: http://dx.doi.org/10.3329/jcamr.v5i2.37066

ORIGINAL ARTICLE

open $\bigcirc$ Access

\title{
Anxiety and Academic Performance among Private Medical College Students
}

\author{
Shila Rani Das ${ }^{1}$, Chinmay Biswas ${ }^{2}$
}

${ }^{1}$ Associate Professor, Department of Community Medicine, ZH Sikder Woman's Medical College, Dhaka, Bangladesh; ${ }^{2}$ Consultant
(Dermatology and Venereology), Upazila Health Complex, Dhamrai, Dhaka, Bangladesh

[Received on: 2 January 2018; Reviewed on: 30 March 2018; Accepted on: 19 May 2018; Published on: 1 July 2018]

\section{Abstract}

Background: Medical students are in a huge pressure due to their academic syllabus. Objective: The purpose of the present study was to assess the relationship between anxiety and academic performance among private medical college. Methodology: This cross sectional study was done in private medical College Hospital, Dhaka, Bangladesh and $3^{\text {rd }}$ and $4^{\text {th }}$ year medical student were included. Data was collected by using semi structured Socio-demographic questionnaire and Burn Anxiety Inventory scale and Checklist. Finally all data and results were analyzed using latest version of SPSS software. For descriptive statistics means, medians, SD and range will be calculated as required. Data will be presented in frequency table, bar, pie and scattered diagram as per need. Statistical test chi-square test were used and $\mathrm{p}<0.05$ was consider to be statistically significant. Results: A total number of 200 medical students were studied after fulfilling the inclusion and exclusion criteria. Among them $87.0 \%$ were Muslim; $98.0 \%$ were unmarried; $83.0 \%$ were in nuclear family; family member of $42.5 \%$ respondents had 4 to 6 persons; monthly income of $64.7 \%$ respondents were less than 50,000 Taka; $47.0 \%$ of the respondents' father occupation was businessman. In $1^{\text {st }}$ profession examination $68.0 \%$ in Anatomy, $73 \%$ in Physiology, $76 \%$ in Biochemistry were passed in anatomy. In $1^{\text {st }}$ professional exam, students suffered from moderate to extreme anxiety were passed $78 \%$ and referred $22 \%$ as well as suffered from minimal to mild anxiety were passed $43 \%$ and referred $57 \%$ in Physiology. So there was strong association between the two variables $(\mathrm{p}<0.05)$. Conclusion: Three fifth of the students are suffered from moderate anxiety level and those who are suffered moderate to extreme anxiety passed more and their class attendance are good. [Journal of Current and Advance Medical Research 2018;5(2):68-72]

Keywords: Anxiety; academic performance; private; medical college students

Correspondence: Dr. Shila Rani Das, Associate Professor, Department of Community Medicine, ZH Sikder Woman's Medical College, Dhaka, Bangladesh; Email: dr.shila@yahoo.com; Cell no.: +8801911183906

Cite this article as: Das SR, Biswas C. Anxiety and Academic Performance among Private Medical College Students. J Curr Adv Med Res 2018;5(2):68-72

Funding: This study has been performed without any funding from outside else.

Conflict of Interest: There was no conflict of interest to any of the authors.

Contributions to authors: Das SR \& Biswas C have contributed in protocol preparation, data collection, data analysis upto the report writing; Biswas $C$ has written \& revised the manuscript.

Copyright: (02018. Das \& Biswas. Published by Journal of Current and Advance Medical Research. This article is published under the Creative Commons CC BY-NC License (https://creativecommons.org/licenses/by-nc/4.0/). This license permits use, distribution and reproduction in any medium, provided the original work is properly cited, and is not used for commercial purposes. 


\section{Introduction}

Anxiety is a psychological disorder that is associated with significant suffering and impairment in functioning. It is a blend of thoughts and feelings characterized by a sense of uncontrollability and unpredictability. Anxiety at moderate levels is necessary for efficient functioning and performance. However, at every high levels it may impair normal functioning and performance in a task ${ }^{1}$.

Anxiety is important in education because it helps student prepare for exams. Excessive anxiety may have a detrimental effect on individual performance in tasks that require competence ${ }^{2}$. Medical education is perceived as stressful. High levels of anxiety have been documented in medical students in various studies ${ }^{3}$. Amongst medical students, anxiety has been reported to be due to academic demands, exam, inability to cope helplessness, increased psychological pressure, mental tension and too much work load ${ }^{4}$. The transition from preclinical to clinical training has been identified as a crucial stage of medical school regarding student stress. All this can result in decreased life satisfaction among students ${ }^{5}$.

Stress during medical school can lead to problems later in professional life compromising patient care $^{6}$. Several studies have reported high rates of psychological morbidity amongst medical students using various instruments ${ }^{6}$. Performance in academic life demands all aspects of well-being, those that include physical, social, emotional, spiritual and psychological well-being ${ }^{7}$. Students who are physically and psychologically stable are expected to perform better compared to those who are not physically, mentally and psychologically fit. Grade Point Average (GPA) is widely used as a measure of academic performance which is obtained by dividing the total amount of grade points scored by the total amount of credit hours attempted. A GPA equal to 3.0 of higher indicates good performance by the students ${ }^{7}$. The purpose of the present study was to assess the relationship between anxiety and academic performance among private medical college.

\section{Methodology}

This cross-sectional study was conducted in Private Medical College, Dhaka, Bangladesh to find out the level of anxiety and it's associated among private medical students and their academic performance. This study was carried out from
January 2013 to December 2013 for a period of one year. The sample were selected randomly from the private medical college. The $3^{\text {rd }}$ and $4^{\text {th }}$ year medical college students were included in this study as per the inclusion and exclusion criteria. Data were collected by using semi structured socio-demographic questionnaire and Burn Anxiety Inventory scale and Checklist.

After taking verbal consent from the students data was collected by face to face interview ensuring privacy and confidentiality and reviewing routinely kept academic record. Before collection of data pretesting of questionnaire and checklist was done. Data processing involves categorizing of data, coding and summarizing the data and entry of data into the software SPSS. Anxiety score was constructed by summation of all of the anxiety scales.

Analysis was performed using latest version of SPSS software. For descriptive statistics means, medians, standard deviations and range for numerical data and frequencies and proportions for categorical data will be calculated as required. For inferential statistics, Chi-square test was used. Data will be presented in frequency table, bar, pie and scattered diagram as per need. Statistical test chi-square test were used and $p<0.05$ was consider to be statistically significant.

\section{Results}

A total number of 200 medical students were studied after fulfilling the inclusion and exclusion criteria.

In this study conducted to private medical college $85.0 \%$ were age of 21 years and only $3.0 \%$ were belonging to 24 years; $87.0 \%$ were Muslim; $10.0 \%$ were Hindu and $2.0 \%$ were Buddha.

However, $98.0 \%$ were unmarried, $83.0 \%$ live in nuclear family $18 \%$ live in joint family. $42.5 \%$ respondents family member were 4-6 persons, $35 \%$ family member were 7 to 10 . $64.7 \%$ respondents monthly income of the parents were less than $50,000 \mathrm{Tk}, 29.5 \%$ were 50001 to $1 \mathrm{lac}$ Taka, 5.8\% were more than 1 Lac taka. $68.0 \%$ live in hostel, $32.0 \%$ live in home. $47.0 \%$ fathers' occupation was businessman, $33.0 \%$ was service holder, $7 \%$ was physician, $1.0 \%$ farmer, $55.0 \%$ were other groups.79.0\% respondents mother was housewife, $10.0 \%$ was service holder and $4.0 \%$ physician (Table 1). 
Table 1: Distribution of respondents by Sociodemographic Characteristic

\begin{tabular}{|c|c|c|}
\hline Variables & Frequency & Percent \\
\hline \multicolumn{3}{|l|}{ Religion } \\
\hline Islam & 174 & 87.0 \\
\hline Hindu & 20 & 10.0 \\
\hline Buddha & 04 & 2.0 \\
\hline Christian & 02 & 1.0 \\
\hline \multicolumn{3}{|l|}{ Marital status } \\
\hline Married & 4 & 2.0 \\
\hline Unmarried & 196 & 98.0 \\
\hline \multicolumn{3}{|l|}{ Type of family } \\
\hline Nuclear family & 166 & 83.0 \\
\hline Joint family & 34 & 18.0 \\
\hline \multicolumn{3}{|c|}{ Monthly income of parents } \\
\hline$\leq 50000$ & 129 & 64.7 \\
\hline $50000-100000 \mathrm{Tk}$ & 59 & 29.5 \\
\hline$\geq 100000 \mathrm{Tk}$ & 12 & $5.8 \%$ \\
\hline \multicolumn{3}{|c|}{ Residence of respondents } \\
\hline Live in hostel & 136 & 68.0 \\
\hline Live in home & 64 & 32.0 \\
\hline \multicolumn{3}{|c|}{ Father's Occupation } \\
\hline Businessman & 94 & 47.0 \\
\hline Service holder & 66 & 33.0 \\
\hline Teacher & 14 & 7.0 \\
\hline
\end{tabular}

\begin{tabular}{|l|l|l|}
\hline Physician & 14 & 7.0 \\
\hline Farmer \& Others & 12 & 6.0 \\
\hline
\end{tabular}

Students passed 68\% in Anatomy, $73 \%$ in Physiology, $76 \%$ in Biochemistry as well as $32 \%$ in Anatomy, 24\% in Physiology and 23\% in Biochemistry failed (Table 2).

Table 2: Distribution of Respondents by Subject wise in $1^{\text {st }}$ Professional Examination

\begin{tabular}{|l|l|l|l|}
\hline Points & Anatomy & Physiology & Biochem \\
\hline Distinction & $0(0.0)$ & $6(3.0)$ & $2(1.0)$ \\
\hline Passed & $136(68.0)$ & $146(73.0)$ & $153(76.5)$ \\
\hline Referred & $64(32.0)$ & $48(24.0)$ & $45(22.5)$ \\
\hline Total & $\mathbf{2 0 0}(\mathbf{1 0 0 . 0})$ & $\mathbf{2 0 0}(\mathbf{1 0 0 . 0})$ & $\mathbf{2 0 0}(\mathbf{1 0 0 . 0})$ \\
\hline Biochem= Biochemistry & &
\end{tabular}

Performance of $1^{\text {st }}$ term examination result, students were passed about $43 \%$ in physiology, $61 \%$ in Microbiology, $48 \%$ in Pharmacology, $53 \%$ in Forensic Medicine and 55\% in Community medicine as well as students were referred about 54\% in Pathology, 37\% in Microbiology, $47 \%$ in Pharmacology, $42 \%$ in Forensic Medicine and $47 \%$ in Community medicine (Table 3 ).

Table 3: Distribution of Respondents by Performance of 1st Term Examination

\begin{tabular}{|c|c|c|c|c|c|}
\hline Points & Pathology & Microbiology & Pharmacology & $\begin{array}{l}\text { Forensic } \\
\text { Medicine }\end{array}$ & $\begin{array}{l}\text { Community } \\
\text { Medicine }\end{array}$ \\
\hline Distinction & $6(3.0 \%)$ & $6(3.0 \%)$ & $10(5.0 \%)$ & $10(5.0 \%)$ & $6(3.0 \%)$ \\
\hline Passed & $86(42.0 \%)$ & $121(60.5 \%)$ & $96(48.0 \%)$ & $106(53.0 \%)$ & $110(55.0 \%)$ \\
\hline Referred & $108(54.0 \%)$ & $73(36.5 \%)$ & $94(47.0 \%)$ & $84(42.0 \%)$ & $84(42.0 \%)$ \\
\hline Total & $200(100.0 \%)$ & $200(100.0 \%)$ & $200(100.0 \%)$ & $200(100.0 \%)$ & $200(100.0 \%)$ \\
\hline
\end{tabular}

In $1^{\text {st }}$ professional exam, students suffered from moderate to extreme anxiety were passed $78 \%$ and referred $22 \%$ as well as suffered from minimal to mild anxiety were passed $43 \%$ and referred $57 \%$ in Physiology. So there was strong association between the two variables $(\mathrm{p}=<0.05)$ (Table 4$)$.

In this study $32.0 \%$ students were in moderate anxiety; $29.0 \%$ were in severe anxiety; $20.0 \%$ were in mild anxiety; $13.0 \%$ were in extreme anxiety and $7.0 \%$ had borderline anxiety (Figure $1)$.
Table 4: Relationship between Anxiety level and Academic performance (1st Professional Exam of Physiology)

\begin{tabular}{|l|c|c|}
\hline Score of Anxiety & Passed & Referred \\
\hline Minimal to mild & $6(42.86 \%)$ & $8(57.14 \%)$ \\
\hline Moderate toextreme & $145(77.86 \%)$ & $41(22.04 \%)$ \\
\hline Total & $\mathbf{1 5 1}(\mathbf{7 5 . 5 \%})$ & $\mathbf{4 8}(\mathbf{2 4 . 5 \%})$ \\
\hline P value $=0.0003$ & & \\
\hline
\end{tabular}

Those class attendance good (57\%) suffered moderate to extreme anxiety (Table 5). 


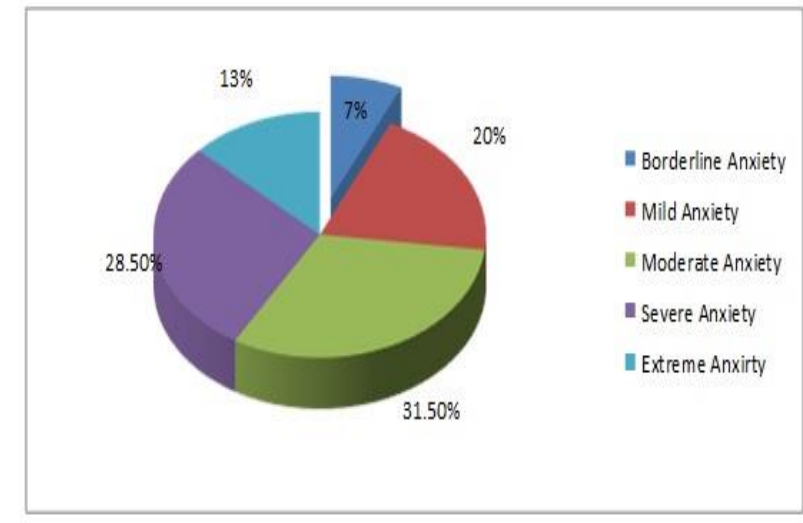

Figure I: Showing distribution of respondents by their score of anxiety

Respondents were passed $46 \%$ and referred in forensic medicine whose monthly income less than $50000 \mathrm{Tk}$. There was strong association between monthly family income of parents and academic performance $(\mathrm{P} \leq 0.05)$ (Table 6).

Table 5: Relationship between Anxiety level and Academic performance (class attendance Pharmacology)

\begin{tabular}{|l|l|l|}
\hline Score of Anxiety & \multicolumn{1}{c}{ Passed } & \multicolumn{1}{c|}{ Referred } \\
\hline Minimal to mild & $2(14.28 \%)$ & $12(85.72 \%)$ \\
\hline Moderate toextreme & $79(42.86 \%)$ & $107(57.53 \%)$ \\
\hline Total & $\mathbf{8 1}(\mathbf{4 0 . 5 \%})$ & $\mathbf{1 1 9}(\mathbf{2 4 . 5 \% )}$ \\
\hline P value $=0.04$ & & \\
\hline
\end{tabular}

Those respondents residing in nuclear family passed more (69\%) in microbiology term. And there was strong association between family type and academic performance (Table 7).

Table 6: Relationship between Monthly family income \& Academic performance

\begin{tabular}{|c|c|c|}
\hline $\begin{array}{l}\text { Monthly } \\
\text { Income }\end{array}$ & Passed & Referred \\
\hline$\leq \mathbf{5 0 0 0 0}$ & $56(45.5 \%)$ & $67(54.5 \%)$ \\
\hline$\geq 50000$ & $60(77.9 \%)$ & $17(22.1 \%)$ \\
\hline Total & $116(58 \%)$ & $84(42 \%)$ \\
\hline
\end{tabular}

\section{Discussion}

Anxiety is a serious problem for students because it interferes with their ability to think and perform during the tests. Medical students experience anxious and stressful environment throughout their stay at medical school. Inability to cope with stressful situations lead to worrisome outcomes in personal and social lives of the students.
According to this study, there was a positive relationship between test anxiety and educational performance greater the anxiety level, greater the chances of increase in educational performance.

Table 7: Relationship between Academic performance and anxiety related factors among family type

\begin{tabular}{|c|c|c|}
\hline $\begin{array}{l}\text { Family } \\
\text { Type }\end{array}$ & Passed & Referred \\
\hline Nuclear & $141(69.1 \%)$ & $51(30.9 \%)$ \\
\hline Joint & $16(45.7 \%)$ & $19(54.3 \%)$ \\
\hline Total & $130(65 \%)$ & $70(35 \%)$ \\
\hline
\end{tabular}

This study revealed that $31.0 \%$ students were in moderate anxiety period and $13 \%$ crossed the severe anxiety to extreme. It is comparable to the prevalence of anxiety reported in $\mathrm{US}^{8}(49 \%)$, Turkey $^{9}(27.1 \%)$. Medical students have to deal with stressors specific to medical school in addition to normal stressors of everyday life which explains this high prevalence of anxiety and depression in their $1^{\text {st }}$ professional exam. Students were about $68.0 \%$ in anatomy, $73.5 \%$ in Physiology and $76.0 \%$ in Biochemistry as well as students were referred about 325 in Anatomy, 24\% in Physiology and 23\% in Biochemistry.

\section{Conclusion}

This study has been revealed that about three fifth of the students are suffered from moderate anxiety level. And the students who are suffered moderate to extreme anxiety have passed more and their class attendance is good. Those who reside in the hostels have good academic performance. Those respondents whose monthly family income is below average has poor academic performance. When students are anxious before and during exam, test anxiety has a significant and effective impact on their academic performance.

To effectively manage test anxiety, students can be helped by teachers, parents and educational administrators through use of cognitive, affective and behavioral strategies. Students must be fully informed nature and duration of course by respective departments for the successful completion of course. However further research is needed to improve understanding the causes and consequences of medical student distress and to investigate potential solution. 


\section{References}

1. Bramness JG, Fixdal TC, Vaglum P. Effect of medical school stress on the mental health of medical students in early and late clinical curriculum. Acta Psychiatrica Scandinavica. 1991;84(4):340-5

2. Chew BH, Zain AM, Hassan F. Emotional intelligence and academic performance in first and final year medical students: a cross-sectional study. BMC medical education. 2013;13(1):44

3. Davidson RA. Relationship of study approach and exam performance. Journal of Accounting Education. 2002;20(1):29-44

4. Inam SN, Saqib A, Alam E. Prevalence of anxiety and depression among medical students of private university. Journal-Pakistan Medical Association. 2003;53(2):44-6

5. Jadoon NA, Yaqoob R, Raza A, Shehzad MA, Zeshan SC. Anxiety and depression among medical students: a cross-sectional study. JPMA. The Journal of the Pakistan Medical Association. 2010;60(8):699-702
6. Dyrbye LN, Thomas MR, Shanafelt TD. Systematic review of depression, anxiety, and other indicators of psychological distress among US and Canadian medical students. Academic Medicine. 2006;81(4):354-73

7. Hemmerich JA, Elstein AS, Schwarze ML, Moliski EG, Dale W. Risk as feelings in the effect of patient outcomes on physicians' future treatment decisions: A randomized trial and manipulation validation. Social science \& medicine. 2012;75(2):367-76

8. Aktekin M, Karaman T, Senol YY, Erdem S, Erengin H, Akaydin M. Anxiety, depression and stressful life events among medical students: a prospective study in Antalya, Turkey. Medical education. 2001;35(1):12-7

9. McManus IC, Richards P, Winder BC, Sproston KA. Clinical experience, performance in final examinations, and learning style in medical students: prospective study. BMJ. 1998;316(7128):345-50 